\title{
A missed traumatic atlanto-axial rotatory subluxation in an adult patient: case report
}

This article was published in the following Dove Medical Press journal: Open Access Emergency Medicine

\author{
Bardia Barimani' \\ Rayan Fairag ${ }^{1,2}$ \\ Fahad Abduljabbar ${ }^{1,2}$ \\ Ahmed Aoude' \\ Carlo Santaguida' \\ Jean Ouellet' \\ Michael Weber ${ }^{\prime}$
}

'McGill Scoliosis and Spine Centre, McGill University Health Centre, Montreal, QC, Canada; ${ }^{2}$ Department of Orthopedic Surgery, King Abdulaziz University, Jeddah, Saudi Arabia
Correspondence: Bardia Barimani Montreal General Hospital, McGill University Health Centre, 1650 Cedar Avenue, T8-200, Montreal, QC, H3G

IA4, Canada

$\mathrm{Tel}+\mathrm{I} 5 \mathrm{I} 49348508$

Fax +I 5149348283

Email bardia.barimani@mail.mcgill.ca
Background: Traumatic atlanto-axial rotatory subluxation (AARS) in an adult is a rare condition, which if left untreated can be fatal. In addition to this, many symptoms experienced such as neck pain and stiffness are non-specific which often leads to misdiagnosis, thus delaying definitive treatment. AARS can be divided into traumatic and non-traumatic causes with the latter generally encompassing congenital cervical spine abnormalities.

Case presentation: We present a case of a 66-year-old female with traumatic rotatory AARS, which was initially misdiagnosed in the emergency department. This patient was subsequently recalled to the hospital when the misdiagnosis was spotted the following day from imaging results. The patient was initially managed conservatively as an inpatient using head halter cervical traction which proved to give good clinical reduction allowing discharge with Miami J upon ambulation. Upon follow up the patient was experiencing continuous pain but remained neurovascularly intact. She thus opted for definitive management with $\mathrm{C} 1-\mathrm{C} 2$ stabilization with an open reduction and internal fixation.

Conclusion: This case demonstrates the importance of having a high index of suspicion to diagnose AARS in cervical spine trauma presenting to the emergency department, until exclusion can be made using imaging and clinical examination.

Keywords: atlanto-axial subluxation, torticollis, atlanto-axial joint, atlanto-axial fixation, rotatory, traumatic

\section{Background}

Cervical spine trauma is a common occurrence, with injury of the cervical spine being reported to occur in $2.4 \%$ of blunt trauma victims. ${ }^{1}$ These injuries can vary in severity, and can range from simple sprains to more serious orthopedic and neurological injuries involving fracture and/or dislocation. A rare cervical spine injury is atlanto-axial rotatory subluxation (AARS) and is often missed at primary presentation with patients usually presenting with neck pain and stiffness. ${ }^{2}$ Torticollis is frequently also experienced; this is a head tilt toward the ipsilateral side with chin rotation toward the contralateral side of the affected region. ${ }^{3}$ In addition to this, rare symptoms such as nystagmus and loss of vision can also be observed. ${ }^{4}$ The causes of AARS can be divided into traumatic and nontraumatic. Non-traumatic causes usually involve congenital cervical spine abnormalities, head and neck infection and tumors of the cervical spine, ordinarily seen in the pediatric population. ${ }^{5}$ Traumatic causes of torticollis include cervical muscular injury, cervical spine fractures, atlanto-axial dislocation and AARS, as with this case. Accurate and timely diagnosis is crucial as this type of injury can be life-threatening if left untreated. 
We encountered a traumatic AARS in an otherwise healthy adult patient which was misdiagnosed by the emergency department and subsequently treated with atlanto-axial fusion. We aim to improve awareness of this condition to allow for early diagnosis and appropriate management.

\section{Case presentation}

A 66-year-old otherwise healthy female, presented to the emergency department with 2-week duration of neck pain. The patient experienced sudden onset of neck pain since her head was forcibly jolted during a religious ritual. Her examination by the emergency department revealed a head tilt to the left side with no neck tenderness. She was neurologically intact.

A computed tomography (CT) scan of the cervical spine was conducted to rule out a fracture which was preliminarily reported to have widening of the atlanto-dens interval (ADI) measuring approximately $6 \mathrm{~mm}$ (normal less than $3 \mathrm{~mm})^{1}$ (Figure 1). No fracture was noted and overall alignment was normal. As examination findings (ADI excluded) were found to be normal, the patient was discharged with advice to return if any worsening symptoms.

The following morning, the CT scan was reviewed by the radiologist attending who found significant rotation of $\mathrm{C} 1$ on C2 with almost complete loss of articular contact involving the right side (Figure 2). These findings are compatible with a type II AARS as per the Fielding and Hawking classification ${ }^{2}$ requiring prompt spine consultation. In addition to this, there was gapping on the left $\mathrm{C} 1-\mathrm{C} 2$ articulation and compression on the right side (Figure 3 ). The image impressions were relayed to the emergency department and the patient was contacted to present herself to the emergency department for reassessment as soon as possible.

After the patient's arrival to the emergency department, she was promptly referred to the orthopedic spine service.

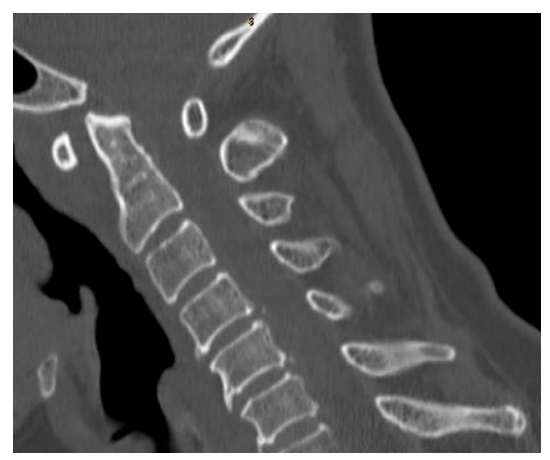

Figure I Computed tomography scan showing a sagittal cut of the cervical spine with an increased atlanto-dens interval $(6 \mathrm{~mm})$.
The spine team physical examination showed that the patient had torticollis with her neck tilted to the right side and rotated toward the left side. She had mid line tenderness on palpation of the posterior cervical spine. Her active and passive range of motion was restricted secondary to pain. The patient's motor and sensory examination was unremarkable and she did not have upper motor neuron lesion signs. The patient was admitted for conservative management with head halter cervical traction. After 7 days of treatment as an in-patient, she was reduced clinically and discharged with the recommendation of home halter traction and the use of a Miami J collar when ambulating. Follow up in spine clinic was then organized for 2 weeks following discharge.

The patient was subsequently seen in clinic where she was complaining of continuous severe neck pain not controlled by narcotics. There was no change in her neurological status but she felt that her neck was tilted once again. Follow-up standing X-ray showed persistent subluxation of $\mathrm{C} 1-\mathrm{C} 2$ with an increased ADI (Figure 4). Therefore, given failure of conservative management and persistent pain, a thorough discussion was conducted with the patient regarding further
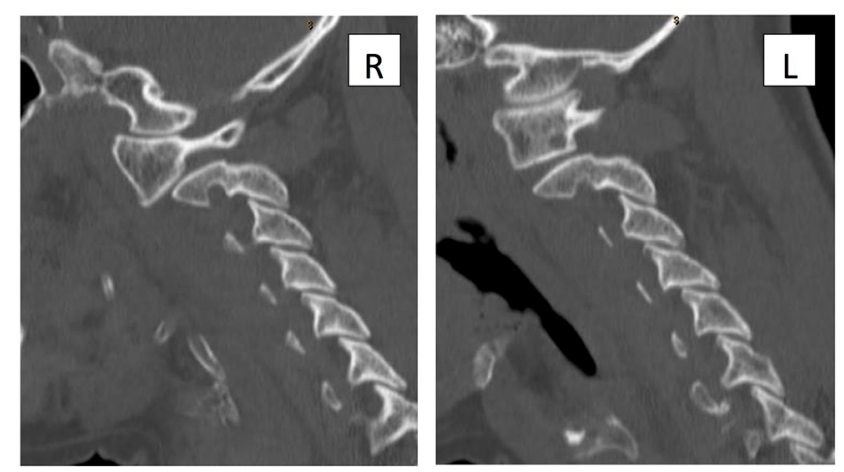

Figure 2 Computed tomography scan showing sagittal cuts of the cervical spine with significant rotation of $\mathrm{Cl}$ on $\mathrm{C} 2$ with almost complete loss of articular contact involving the right side.

Abbreviations: R, right; L, left.

\section{A}
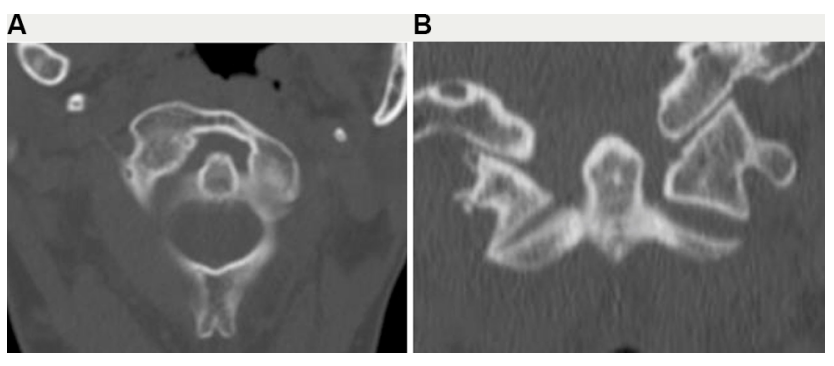

Figure 3 (A) Computed tomography scan of the upper cervical spine showing an axial cut which demonstrates a type II atlanto-axial rotatory subluxation which is consistent with the patient's neck position (rotation to the contralateral side). (B) Coronal cut showing gapping on the left $\mathrm{Cl}-\mathrm{C} 2$ articulation and compression on the right side, which is consistent with the patient's neck position (ipsilateral head tilt). 


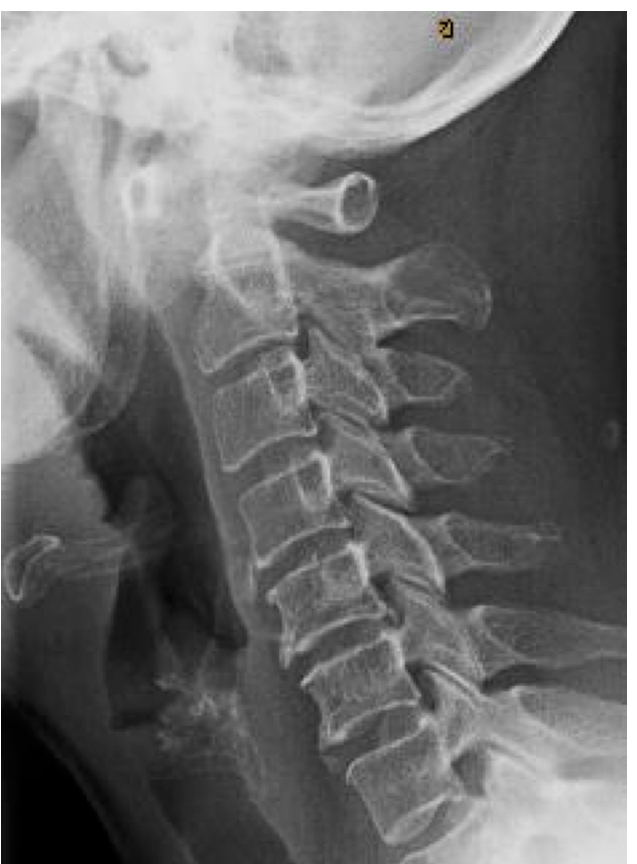

Figure 4 Lateral cervical spine standing $X$-ray after 3 weeks of non-operative management showing persistent increased atlanto-dens interval.

treatment. The patient opted for operative management and underwent $\mathrm{C} 1-\mathrm{C} 2$ stabilization with an open reduction and internal fixation (Figure 5). The patient was seen at her 3-month post-operative follow-up and had decreased pain with normal neurological status. However, her cervical range of motion was decreased as expected given her fixation.

\section{Discussion}

The atlanto-axial joint is one of the most active joints in the human body, reported to be under motion for the whole day. ${ }^{6}$ The natural horizontal position of the facet joints between the atlas and the axis allow a rotation of approximately $90^{\circ}$ to either side. The transverse ligament stabilizes the atlantoaxial joint and prevents anterior motion of the atlas on the axis anteroposteriorly. Alar ligaments, which pass from the posterolateral apex of the odontoid to the occipital processes, restrict over-rotation and anterior shifting of the atlas on the axis. ${ }^{7,8}$ Atlanto-axial joint subluxation can be secondary to nontraumatic or traumatic causes. Non-traumatic causes involve genetic conditions such as Down's syndrome and Marfan's syndrome, congenital deformities of the spine, ligamentous laxity, metastatic tumors of the neck region and inflammatory diseases. ${ }^{3}$ Non-traumatic rotatory atlanto-axial subluxation associated with inflammation or infectious processes in the head and neck region is known as Grisel's syndrome. ${ }^{9}$

Traumatic rotatory subluxation typically occurs in children, but rare adult cases do occur. ${ }^{10}$ Factors that predispose
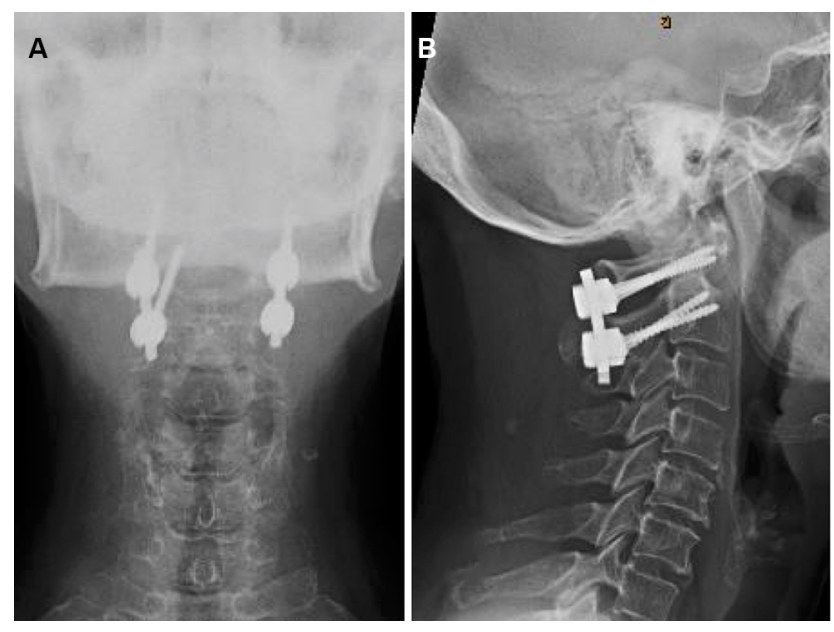

Figure 5 Anteroposterior (A) and lateral (B) views of the cervical spine showing posterior $\mathrm{Cl}-\mathrm{C} 2$ instrumentation with restored normal atlanto-dens interval.

children to an increase in incidence of AARS include a large head, underdeveloped neck musculature, an increased laxity of the joint capsule, a rotational angle greater than $45^{\circ}$ and horizontal configuration of the $\mathrm{C} 1-\mathrm{C} 2$ articular facets. ${ }^{11} \mathrm{It}$ is a rare condition that requires a low index of suspicion in order to make a prompt diagnosis. Most reported cases are in the pediatric population. ${ }^{12}$ Few cases of traumatic rotatory injuries of the atlanto-axial joint in adults have been described in the literature. ${ }^{5,13,14}$ Patients mainly present with neck pain or torticollis that is associated with ipsilateral head tilt, rotation to the contralateral side and decreased range of motion. Neurological deficit such as cervical myelopathy and occipital neuralgia can occur depending on severity. ${ }^{5}$ Rotatory atlanto-axial subluxation has been classified by Fielding and Hawkins ${ }^{15}$ and is grouped into four types based on the degree of displacement of the odontoid process relative to the facet of atlas radiologically. Type 1 describes rotatory subluxation without anterior displacement of the atlas $(\leq 3 \mathrm{~mm})$, type 2 includes anterior displacement of $3 \mathrm{~mm}$ to $5 \mathrm{~mm}$, type 3 has $>5$ $\mathrm{mm}$ of anterior displacement and type 4 is used for posterior displacement of the atlas.

Radiographic evidence associated with this type injury is very difficult to interpret due to pain and deformity restricting optimum head position. However, adequate lateral cervical spine and lateral skull views in flexion often help identify the relative positions of the atlas and axis. ${ }^{16} \mathrm{CT}$ scan remains the gold standard imaging modality to identify these injuries. MRI can give further information regarding surrounding ligamentous structures, severity of injury and possible etiology. ${ }^{8}$

Management of AARS depends on the multiple factors including the severity, reducibility and timing of presentation. ${ }^{7}$ Closed reduction and immobilization with a halo ring or a 
collar is an acceptable treatment for patients with acute presentation. On the other hand, delayed presentation ( $>4$ weeks) makes reduction harder and difficult to maintain. ${ }^{7}$ Singh et $\mathrm{al}^{11}$ reported a successful closed reduction and halo immobilization for a 25-year-old female within 24 hours of her injury. Four case reports reported a successful closed reduction and collar immobilization within few hours after the injury. ${ }^{13,17,18}$ Interestingly, our patient was a 66-year-old female with traumatic rotatory subluxation of the atlanto-axial joint with failure of conservative management due to late presentation. Early diagnosis is imperative, as the length of the time between the injury and its reduction correlates with rates of recurrence and failure of reduction by non-surgical techniques. ${ }^{11}$

Our case demonstrates the vague and nonspecific symptoms of rotatory subluxation of the atlanto-axial joint, which can be misleading on initial presentation. Symptoms of neck pain as well as reduced neck range of movement can mimic simple conditions such as muscle spasm. For this reason, clinicians should be hypervigilant of AARS in patients following cervical spine trauma, to facilitate timely diagnosis and subsequent appropriate management.

\section{Conclusion}

In summary, AARS is a rare condition that can occur in people who are otherwise healthy. If diagnosed early, it can be effectively treated with conservative management consisting of traction and neck immobilization. Recurrence rate and failure of reduction correlates with length of time from injury to reduction and in the case of recurrence or failure of reduction, surgical intervention is warranted. Clinically it is difficult to identify subluxation of the atlanto-axial joint due to its nonspecific presentation; however, we recommend having a high level of suspicion for patients presenting with traumatic torticollis.

\section{Consent}

Written consent has been provided by the patient to have the case details and accompanying images published.

\section{Disclosure}

The authors report no conflicts of interest in this work.

\section{References}

1. Torretti JA, Sengupta DK. Cervical spine trauma. Indian J Orthop. 2007;41(4):255-267.

2. Weisskopf M, Naeve D, Ruf M, Harms J, Jeszenszky D. Therapeutic options and results following fixed atlantoaxial rotatory dislocations. Eur Spine J. 2005;14(1):61-68.

3. Powell EC, Leonard JR, Olsen CS, Jaffe DM, Anders J, Leonard JC. Atlantoaxial rotatory subluxation in children. Pediatr Emerg Care. 2017;33(2):86-91.

4. Eghbal K, Derakhshan N, Haghighat A. Ocular manifestation of a cervical spine injury: an adult case of traumatic atlantoaxial rotatory subluxation manifesting with nystagmus. World Neurosurgery. 2017;101(817):817.e1-817.e3.

5. Jeon SW, Jeong JH, Moon SM, Choi SK. Atlantoaxial rotatory fixation in adults patient. $J$ Korean Neurosurg Soc. 2009;45(4):246-248.

6. Bland JH. Rheumatoid subluxation of the cervical spine. J Rheumatol. 1990;17(2):134.

7. Castel E, Benazet JP, Samaha C, Charlot N, Morin O, Saillant G. Delayed closed reduction of rotatory atlantoaxial dislocation in an adult. Eur Spine J. 2001;10(5):449-453.

8. Gourin CG, Kaper B, Abdu WA, Donegan JO. Nontraumatic atlantoaxial subluxation after retropharyngeal cellulitis: Grisel's syndrome. Am J Otolaryngol. 2002;23(1):60-65.

9. Beier AD, Vachhrajani S, Bayerl SH, Aguilar CY, Lamberti-Pasculli M, Drake JM. Rotatory subluxation: experience from the hospital for sick children. J Neurosurg Pediatr. 2012;9(2):144-148.

10. Fuentes S, Bouillot P, Palombi O, Ducolombier A, Desgeorges M. Traumatic atlantoaxial rotatory dislocation with odontoid fracture: case report and review. Spine. 2001;26(7):830-834.

11. Singh VK, Singh PK, Balakrishnan SK, Leitao J. Traumatic bilateral atlantoaxial rotatory subluxation mimicking as torticollis in an adult female. J Clin Neurosci. 2009;16(5):721-722.

12. Corluy L, Pison L, Lauweryns P, Samson I, Westhovens R. An unusual non-traumatic atlantoaxial subluxation in an adult patient: Grisel's syndrome. Clin Rheumatol. 2004;23(2):182-183.

13. Venkatesan M, Bhatt R, Newey ML. Traumatic atlantoaxial rotatory subluxation (TAARS) in adults: a report of two cases and literature review. Injury. 2012;43(7):1212-1215.

14. Hawi N, Alfke D, Liodakis E, et al. Case report of a traumatic atlantoaxial rotatory subluxation with bilateral locked cervical facets: management, treatment, and outcome. Case Rep Orthop. 2016;2016: 7308653.

15. Fielding JW, Hawkins RJ. Atlanto-axial rotatory fixation. (Fixed rotatory subluxation of the atlanto-axial joint). J Bone Joint Surg Am. 1977;59(1):37-44.

16. Roche CJ, O'Malley M, Dorgan JC, Carty HM. A pictorial review of atlanto-axial rotatory fixation: key points for the radiologist. Clin Radiol. 2001;56(12):947-958.

17. Meza Escobar LE, Osterhoff G, Ossendorf C, Wanner GA, Simmen HP, Werner CM. Traumatic atlantoaxial rotatory subluxation in an adolescent: a case report. J Med Case Rep. 2012;6(1):27.

18. Crook TB, Eynon CA. Traumatic atlantoaxial rotatory subluxation. Emerg Med J. 2005;22(9):671-672.
Open Access Emergency Medicine

\section{Publish your work in this journal}

The Open Access Emergency Medicine is an international, peerreviewed, open access journal publishing original research, reports, editorials, reviews and commentaries on all aspects of emergency medicine. The manuscript management system is completely online and includes a very quick and fair peer-review system, which is all

\section{Dovepress}

easy to use. Visit http://www.dovepress.com/testimonials.php to read real quotes from published authors. 